\title{
Insubordinación estética en el Movimiento Unitario Mujeres por la vida. Un análisis conceptual a partir de Jacques Rancière y Hans Robert Jauss
}

\author{
Aesthetic insubordination in the Women's Unity Movement \\ for Life a conceptual analysis based on Jacques Rancière and \\ Hans Robert Jauss
}

Insubordinação estética no Movimiento Unitario Mujeres por la vida. Uma análise conceitual a partir de Jacques Rancière e Hans Robert Jauss

Paula Poblete Vargas*

\begin{abstract}
RESUMEN:
En el presente artículo analizaré las acciones y escritos de Mujeres por la vida, trabajo de carácter estético político que se realizó en Chile durante la dictadura militar entre 1983 y 1989. Revisaré sus acciones, intervenciones y documentos a partir de algunos conceptos propuestos por Jacques Rancière y Hans Robert Jauss. $\mathrm{Al}$ analizar estos trabajos desde estas perspectivas estéticas contemporáneas se aprecia su singular condición que aquí describiremos como insubordinación estética.
\end{abstract}

\section{SUMMARY:}

This article will analyze Women for Life's actions and writings, a work of political, aesthetic character carried out in Chile during the military dictatorship between 1983 and 1989. We will review their actions, interventions, and documents based on some
Palabras clave: estética, mujeres, arte crítico, resistencia, insubordinación

Keywords: aesthetics, women, critical art, resistance, insubordination

\footnotetext{
* Chilena. Licenciada en Filosofía, Universidad ARCIS, Magíster en Investigación en Arte y Creación, Universidad Complutense de Madrid, candidata a Doctora en Bellas Artes, Universidad Complutense de Madrid. El artículo forma parte de la investigación Doctoral financiada por Becas Chile Doctorado en el extranjero CONICYT. Contacto: pobletevargasp@gmail.com
} ORCID: 0000-0003-1339-1509 
concepts proposed by Jacques Rancière and Hans Robert Jauss. Analyzing these works from these contemporary aesthetic perspectives, we can appreciate their unique condition, which we will describe as aesthetic insubordination.

\section{RESUMO:}

No presente artigo, serão analisados as ações e os textos de

Palavras-chave: Mujeres por la vida, um trabalho de caráter estético e político realizado no Chile durante a ditadura militar entre 1983 e 1989. estética, mulheres, Serão revisados suas ações, intervenções e documentos a pararte crítica, tir de alguns conceitos propostos por Jacques Rancière e Hans resistência, Robert Jauss. Através da análise destes trabalhos a partir destas insubordinação perspectivas estéticas contemporâneas, é possível apreciar sua singular condição que será aqui descrita como insubordinação estética. 


\title{
1. Mujeres por la vida
}

\begin{abstract}
"Hoy velaremos en las calles, llamando a todas las mujeres a abandonar el silencio, a gritar NO + DICTADURA. Porque tenemos la esperanza cierta que esta tierra está habitada por millones de justos y tan sólo un puñado de maleantes".
\end{abstract}

MUJERES POR LA VIDA: NO + DICTADURAS, jVIVIREMOS!

El Movimiento Unitario Mujeres por la vida surge en el año 1983, luego de la inmolación y posterior muerte de Sebastián Acevedo ${ }^{1}$. La muerte de este trabajador de la construcción, de 50 años, deja en evidencia la desesperanza con que vivió la desaparición de sus hijos. Según los relatos que él y su esposa pudieron recoger, sus hijos habían sido apresados por civiles armados pertenecientes a la Central Nacional de Informaciones (CNI), organismo de inteligencia responsable de la persecución, secuestro y desaparición de miles de opositores al régimen del dictador Augusto Pinochet. Esta falta de información sobre el paradero de sus hijos lo lleva a tomar la fatal decisión de inmolarse.

El día martes 15 de noviembre de 1983 el diario Las Últimas Noticias narra la asistencia a su funeral como "una muchedumbre, calculada en unas 15 mil personas..., hecho que muestra la conmoción que generó en la ciudad de Concepción y en las diversas localidades de la región del Biobío. Pese a ello, la información entregada por la prensa de esos años sobre la muerte de Sebastián Acevedo es escasa. Es llamativo que, cuando la periodista del reportaje anterior se refiere a las personas que asisten a su funeral como "una muchedumbre", le otorga una connotación política a ese grupo. Sin embargo, la noticia aparece en las páginas policiales de distintos diarios nacionales.

1 Sebastián Acevedo Becerra fue un ciudadano chileno, obrero de la ciudad de Concepción. Dos de sus cuatro hijos, María Candelaria y Galo, fueron detenidos el 9 de noviembre de 1983 por agentes del Estado, específicamente de la Central Nacional de Informaciones (CNI). Buscó a sus hijos por diversos lugares, recorrió comisarias, habló con periodistas de diferentes medios, con autoridades tanto militares como civiles. Fueron tres días de total desesperación en que nadie lo ayudó, nunca pudo obtener información sobre la localización de sus hijos. El día 11 de noviembre de 1983, en un acto desesperado, se roció bencina en sus ropas y les prendió fuego en la plaza de armas de su ciudad, frente a la catedral. Este llamado desgarrador conmovió a muchos penquistas. María Candelaria fue puesta en libertad y pudo despedirse de su padre. Al tiempo volvió a ser detenida. Galo no tuvo la misma suerte que su hermana y no se pudo despedir de su padre, aun cuando cree que, gracias a él, la CNI no lo mató, en virtud de la trascendencia mediática de su caso. 
Esta inmolación es la cara más dura de lo que se vivía en Chile. Una sangrienta dictadura que en 1983 cumplía 10 años en el poder. El 11 de mayo de 1983 tiene lugar la primera protesta nacional contra la dictadura de Pinochet. En un primer momento fue un llamado de los trabajadores del cobre a un paro-protesta que luego fue sumando a distintas organizaciones, desde colectivos poblacionales hasta partidos políticos, además de amplios sectores de la sociedad civil. Para esta protesta se llamó a no concurrir al trabajo, no enviar a los niños a la escuela, no comprar, tocar bocinas y cacerolas. A todas estas acciones se sumaron barricadas durante la noche en distintas comunas del país. El régimen militar nunca esperó el nivel de masividad que tuvo esta protesta y su respuesta no se hizo esperar: una violenta represión. Esta importante jornada marcará el inicio de un ciclo de luchas y protestas que culminará en 1986.

Los años 80 en Chile también son años convulsos en el aspecto económico. Desde la implementación de la nueva Constitución neoliberal, ideada por Pinochet y sus asesores, que traerán una enorme crisis económica y social sumada a la enorme ola de violencia y muerte que no cesaba. En este escenario surge el movimiento social femenino $\mathrm{Mu}-$ jeres por la vida. Nace en solidaridad con ese padre y como respuesta a lo que ellas llamarán: "la cultura de la muerte", es decir, la violencia en ese momento se encontraba instaurada por el Estado chileno, la vida era constantemente vulnerada de manera brutal a través de desapariciones forzadas, asesinatos, torturas, violaciones a manos de agentes del Estado. Mujeres por la Vida se origina para sumarse a la resistencia de los acontecimientos políticos.

“Hoy y no mañana”, escrito el 16 de noviembre de 1983, luego de la muerte de Sebastián Acevedo, es el primer documento escrito por esta agrupación. Allí se presentan como tal y nombran a las mujeres integrantes. En su primera página, Mujeres por la Vida dirán:

Nos une la urgencia de temer por nosotros mismos, como pueblo. Nos reúne el sentimiento y la convicción de que como país, como grupo humano, estamos llegando a un punto límite que exige una acción decidida.

Porque la inmolación de ese padre es una voz que se eleva para todos nosotros, una voz que nos dice - desgarradoramente- que 
HOY Y NO MAÑANA debemos ser capaces de recuperar la cordura, recuperar lo que es propio de una sociedad civilizada.

(...) Para detener este horror se exige un cambio urgente, necesario e indispensable. Un cambio que debe alcanzarse HOY Y NO MANANA, un cambio que exige la suma de voluntades, porque ninguna diferencia puede ser tan grave y tan seria como para dividir a quienes nos oponemos a este sistema de muerte.

Las integrantes son mujeres muy diversas; profesionales, dueñas de casa, militantes de diversos partidos políticos opositores al régimen dictatorial, siendo esto último lo que más llama la atención de la prensa. Son ellas mismas quienes lo recalcan diciendo que han logrado aquello que los hombres nunca han podido: agruparse más allá de sus convicciones políticas. Ellas logran instalarse sobre esas diferencias y así constituir un movimiento que defienda la vida por sobre todo. Consiguen borrar sus diferencias políticas en virtud de terminar con la cultura de la muerte y traer de vuelta la democracia.

El trabajo de resistencia política resulta muy evidente cuando se habla de Mujeres por la vida, pero pocas veces se enfatiza su trabajo visual: acciones, intervenciones callejeras. Este texto propone destacar el trabajo visual que realizan, posicionarlo y situarlo como un trabajo estético, y de esta manera hacerlas ingresar a la escena artística chilena.

Intentaremos diseñar una hoja ruta de su trabajo. Un recorrido por sus acciones y por los documentos que las acompañan, y que son parte fundamental de su trabajo. Nos interesa describir la manera cómo estructuran su discurso de resistencia ${ }^{2}$ en términos visuales.

Las intervenciones que realizan las llaman "acciones relámpago", por su condición efímera. Éstas se ejecutan mayoritariamente en el espacio público, sin contar con recursos asociados para su creación, por lo tanto, al momento de pensar, de crear una acción, ésta debía ser con el mínimo presupuesto ${ }^{3}$, aunque en estricto rigor hablar de

2 Es más, nos interesa cuestionar este concepto de "resistencia", en cuanto consideramos que su trabajo va más allá de resistir.

3 Respecto de los "medios precarios" con que esta agrupación contaba para la realización de sus acciones, podemos destacar la acción "Caminata de mujeres en silencio, ¿me olvidaste?", de 19 de julio de 1988. La frase central de esta acción fue “Soy una víctima de la dictadura: me torturaron, me asesinaron, me desaparecieron. ¿Me olvidaste?". 
"presupuesto" implica un monto con el cual ellas no contaban; en este caso, por lo tanto, debiéramos hablar de "medios precarios". Las maneras de hacer de esta agrupación parten de la idea de romper con la "normalidad" y, asimismo, dar visibilidad a lo que estaba ocurriendo, mostrar cuál era la posición que ellas tenían, y así evidenciar a las mujeres como sujetas políticas activas. Además de romper con la normalidad, estas acciones pretenden ser una forma de interpelación a quienes transitan por la calle. La opinión pública no sabe cuándo, cómo ni dónde se realizarán estas acciones, siendo justamente esto lo que les entrega mayor riqueza. Por esta misma razón no existen muchos documentos o fotografías sobre las diversas acciones callejeras que realizaron. La mayoría de los documentos fotográficos es parte de archivos personales de artistas pertenecientes a la agrupación.

El trabajo acerca del Movimiento Unitario Mujeres por la vida lo dividiremos en acciones/intervenciones y documentos (manifiestos, comunicados, declaraciones públicas, instructivos para asistir a las diversas manifestaciones que convocaban). Estos dos tipos de expresiones se generaban a partir de los diversos acontecimientos políticos del país; era una forma de responder a ellos y, al mismo tiempo, demostrar un posicionamiento político de las mujeres en el espacio público.

Como mencionamos, el público que presenció las acciones no fue muy numeroso, por su carácter efímero. Algunos de los documentos que escribieron Mujeres por la vida fueron publicados en medios de prensa o bien fueron leídos durante las manifestaciones que convocaban. Estas manifestaciones/marchas tuvieron grandes repercusiones, pues congregaron a un gran número de mujeres, sorprendiendo a los transeúntes y a quienes observaban las pantallas de los televisores. Mujeres por la vida acuñó frases tales como: No +, Somos +, frases que hasta el día de hoy han trascendido en nuestra sociedad, especialmente en agrupaciones feministas que hoy revitalizan su trabajo.

Cada mujer llevaba una silueta humana, realizada en cartón pintado de negro, con el nombre de un detenido desaparecido, y la frase " $i$ me olvidaste?" como una gran pregunta. Además de la carta que realizaron para invitar a esta caminata, existe otro documento que confeccionaron para agradecer los aportes realizados para poder llevar a cabo dicha acción. Terminan la carta diciendo: "creemos que un país que olvida, vuelve a repetir su historia. Es necesario sanar más que olvidar”. 
Fue una sorpresa para ellas mismas el gran número de mujeres capaces de "sacar la voz por sus ideales", pues salir a la calle, en dictadura, siempre implicaba un riesgo. Recordado es el Acto realizado en el teatro Caupolicán, llamado: "Hoy y no mañana. ¡Por la Vida! ${ }^{4}$ La Libertad tiene nombre de mujer", que lleva el mismo nombre del manifiesto escrito luego de la muerte de Sebastián Acevedo. Este acto congregó a cerca de diez mil mujeres. En el documento "Declaración e invitación al Acto de Mujeres en el teatro Caupolicán: 29 de diciembre de 1983" dirán:

Las mujeres chilenas nos reuniremos el próximo 29 de diciembre en el Teatro Caupolicán para expresar nuestra decisión de vida. Desde muy diferentes campos de la vida nacional, desde nuestros hogares, nuestras poblaciones, nuestros trabajos y nuestras organizaciones, hemos sabido demostrar nuestra fuerza y valor para sobrevivir a 10 años de muerte: cárceles secretas, torturas, exilios, detenidosdesaparecidos, relegaciones, allanamiento y represiones, abusos de poder y arbitrariedad sobre los sectores más desposeídos.

Hoy nos encontramos frente a la más grave crisis de nuestra historia: la ruina económica, el desgobierno, la corrupción, la represión que aumenta día a día, la cesantía, el hambre, la destrucción de hogares y un clima generalizado de violencia social. Son estas todas expresiones de un vertiginoso espiral, que sabemos donde comienza, pero cuyas repercusiones son imposibles de adivinar ${ }^{5}$.

4 Según señala la prensa de la época (La Tercera, Las Últimas Noticias), destacan 78 agrupaciones firmantes en el documento confeccionado para dicho evento. Entre las agrupaciones que organizaron y convocaron a este acto se encuentran: Movimiento de Emancipación de la Mujer Chilena: MEMCh; Mujeres de Chile: MUDECHI; Agrupación de Familiares de Detenidos-Desaparecidos; Coordinadora Cultural y el Departamento Femenino de la Coordinadora Nacional Sindical. Aun cuando Mujeres por la vida no aparece dentro de las agrupaciones convocantes, sí firman el Manifiesto que dará nombre al evento: Hoy y no Mañana. ¡Por la vida! En un artículo publicado en el diario La Tercera, el 22 de noviembre de 1983, se destaca que: "Las mujeres podrán llevar banderas chilenas y pequeños lienzos o pancartas de organizaciones, pero no llevarán emblemas partidistas, porque hoy en día las mujeres necesitamos unirnos por encima de nuestras ideologías políticas y religiosas. Los problemas son comunes y nos afectan a todas por igual". Como dijo María Asunción Bustos, presidenta de MUDECHI en la conferencia de prensa que recoge Las Últimas Noticias del 29 de diciembre de 1983: "La protagonista del acto es la chilena".

5 Esta cita es parte del libro de Teresa Valdés Las Mujeres y la Dictadura Militar en Chile, anexo III, Editado por FLACSO, Santiago de Chile, pág. 33. 
Proponemos dos lecturas basadas en problemáticas que podemos recoger del trabajo de esta agrupación. En primer lugar, reflexionar a partir de las acciones relámpago, específicamente la idea que esta agrupación tiene sobre quiénes están del otro lado, a quiénes pretende interpelar: la figura de espectador. Lo que vemos y nos interesa destacar aquí es la libertad en que se deja al espectador para que cada cual construya su mirada. El ejercicio que realizará quien está al frente de la acción es un ejercicio activo que lo hace parte de la intervención/acción. Sobre esto es pertinente el concepto de arte crítico, concepto que también tomaremos de Rancière, que se plantea como un arte activo ligado directamente con la idea que mencionamos sobre el espectador y el papel crucial que tiene en la obra, pues él es parte, es quien cierra la obra. En segundo lugar y a través de conceptos pertenecientes a la estética de la recepción de Hans Robert Jauss, reflexionaremos sobre aquello que sucede internamente en las mujeres que pertenecen a esta agrupación, qué las mueve a generar estas acciones como forma de insubordinación estética, conceptualización que proponemos a partir de ambas lecturas.

\section{Espectador y emancipación}

Tanto el concepto de "espectador" como el de "emancipación" están presentes en el trabajo de Mujeres por la vida. Comenzamos refiriéndonos al primero, específicamente a la figura de un espectador activo $^{6}$, que vamos a utilizar para crear un paralelo con el concepto que utiliza Rancière de "espectador emancipado". El espectador emancipado tiene un papel protagónico en la obra, en este caso en la acción. Y, asimismo, el espectador emancipado se encuentra ligado directamente con el arte crítico. ¿Cómo se da esa relación? Rancière dirá que el arte de cualquier época puede llegar a ser un arte crítico si al frente de él está un espectador emancipado, un espectador activo y no sólo un voyeur. Ser un espectador activo y no solo un mirón hace la gran diferencia para pensar en el quehacer de Mujeres por la vida. Si bien ellas no se

6 La idea de un espectador activo es muy importante si pensamos en el arte contemporáneo, en el cual el artista ya no construye su obra sin pensar en el espectador, por lo tanto, ese espectador tiene un papel dentro de la obra, dejó de lado su pasividad. En las intervenciones callejeras, en las acciones artísticas que se realizan en el espacio público, esto tiene una vital relevancia, pues hay una directa interpelación a los transeúntes, una intención de romper su rutina al mismo tiempo que la normalidad. 
pensaban como una agrupación artística, sus acciones sí pueden ser comprendidas como tales, incluso se pueden vincular con las obras y acciones del $\mathrm{CADA}^{7}$, por ejemplo, que sí se consideraba una agrupación artística. Consideramos que su accionar se puede enmarcar en un trabajo claramente estético, pues mezcla el trabajo visual y el posicionamiento político. Para explicar este vínculo nos presta ayuda el análisis de Rancière sobre el reparto de lo sensible: la estética primera, anterior a cualquier experiencia estética o artística. Tal estética primera es el reparto inicial, la manera en que participamos sensiblemente de una experiencia de lo común y su distribución. Estamos frente a prácticas estéticas. Rancière (2000) las define así:

Es a partir de esta estética primera que podemos plantear la cuestión de las "prácticas estéticas", en el sentido en que nosotros las entendemos, es decir formas de visibilidad de prácticas del arte, del lugar que ellas ocupan, de lo que "hacen" a la mirada de lo común (10).

En efecto, el trabajo que realiza este movimiento está basado, justamente, en intervenir la mirada de lo común y poder transformarla. Por otra parte, entenderemos la estética como una distribución de lo sensible mucho antes que una disciplina teórica. Cuando Rancière invita, desde el régimen estético, a pensar en el rol político del arte, invita a pensar precisamente en la forma en que la experiencia estética y la obra de arte, en este caso acciones e intervenciones, actúan en esas condiciones primeras de la sensibilidad. Condiciones que se encuentran en el nivel social, que están determinadas por las formas sociales

7 El CADA (colectivo de acciones de arte) agrupación artística conformada por la escritora Diamela Eltit, la artista visual Lotty Rosenfeld, el sociólogo Fernando Balcells, el poeta Raúl Zurita y el artista visual Juan Castillo. Este colectivo nace en 1979 hasta 1985, año en que realizan su última acción como agrupación. Este colectivo y Mujeres por la vida comparten un claro posicionamiento político además de la forma en que escogen visibilizar los acontecimientos utilizando estrategias similares de acción visual. Además, es importante mencionar que la artista visual Lotty Rosenfeld también formará parte de Mujeres por la vida. Por esta razón no es extraña la cercanía de ambas agrupaciones que queda en evidencia en la obra Viuda, obra que realizan en conjunto, y que además cuenta con la participación de Paz Errázuriz. Esta obra es una fotografía, el retrato de una mujer que mira a la cámara, que mira a los ojos, intentando reflejar a todas las mujeres que han perdido a sus seres queridos, especialmente referida a sus parejas. Esta obra viene a mostrar el claro posicionamiento de resistencia por parte de las mujeres. No es de extrañar que esta obra con un fuerte tinte feminista haya sido realizada cuando el CADA estaba conformado sólo por Eltit y Rosenfeld. 
a través de un reparto del cual no todos participan, e incluso algunos apenas tienen parte. Esta serie de relaciones constituyen un reparto de lo sensible o estética primera: aquellas condiciones primeras de lo sensible en las que nos ubicamos históricamente y que ya operan previamente como una división, distribución o reparto que fija el lugar de cada cual. Estética será definida por Rancière como:

(...) el sistema de formas a priori de lo que se da a sentir. Es un recorte de tiempos y espacios, de lo visible y de lo invisible, de la palabra y el ruido que define a la vez el lugar y la problemática de la política como forma de experiencia. La política trata de lo que vemos y de lo que podemos decir al respecto, sobre quien tiene la competencia para ver y la cualidad para decir, sobre las propiedades de los espacios y de los posibles del tiempo (2000 10).

Pensando en el despliegue del trabajo de Mujeres por la vida, veremos que la ocupación del espacio público hace que más personas puedan participar directamente de estas acciones. Un ejemplo de ello es la acción "Yo voto x democracia", en la que se apela a un interlocutor/espectador activo quien se hace parte de la obra, en este caso de la acción, concibiéndola como parte de su praxis vital. En esta acción que interpela, además de relacionarla con aquello que vivimos, les interesa que aquel que está del otro lado pueda establecer una posición política frente a ello, o bien ser solo quien mira $^{9}$; en ese sentido es una acción libre.

8 La acción "Yo voto x democracia" fue una convocatoria de Mujeres por la vida a una "Jornada Nacional por la Democracia", en Santiago de Chile el 20 de marzo de 1986, en la que llamaban abiertamente a votar simulando un plebiscito. Para esto se instalaron urnas en diversos lugares de la ciudad, y en el voto que se entregaba se instaba a las personas a elegir entre democracia y dictadura. Además, en el voto aparecían llamados a reproducir y distribuir el voto, además de botarlo en la calle. Esta acción fue reprimida fuertemente por fuerzas policiales.

9 Ya hemos hablado de quienes miran. Hacemos la diferencia entre quienes solo miran y quienes son espectadores, para que quede más clara la diferencia política. Pensando en la idea de Rancière de "voyeurs", que traducido sería algo así como "mirones". Y es que el mirón no se hace parte de la obra, no participa de ella; solo mira. El espectador en cambio tiene la intención y la voluntad de participar en la obra, de aprehenderla. Es el espectador el que es un potencial espectador emancipado: aquel que construye con su mirada un arte crítico. De todas maneras, siempre será interesante pensar al mirón, porque, aun cuando no ingrese en la acción, invita a esta agrupación a pensar cómo invitarlo a tomar un papel protagónico. 
En este trabajo comprendemos la figura del espectador como aquella que se revela ante la idea de pertenecer únicamente al arte, puesto que está a la vista su enorme potencial político. En este sentido, el trabajo de Mujeres por la vida, específicamente sus acciones relámpago, se centran en producir "algo" en quien está del otro lado, en quien mira. Vemos que la intención está en que el espectador deje de ser una figura pasiva y que, a través de aquello, construya una posición política. Esto es el punto de partida en cuanto a la participación que el espectador puede llegar a tener en la acción. En el ejemplo anterior, "Yo voto $\mathrm{x}$ democracia”, la participación de la gente que está en la calle va más allá de ser un espectador: en este caso la gente es la que desarrolla la acción. Es decir, existe una borradura entre quienes generan la acciónintervención callejera y quienes la reciben. No sabemos si Mujeres por la vida era consciente de este ejercicio estético. Lo que sí sabemos, y ellas mismas se encargan de aclararlo, es que se niegan tajantemente el olvido, tanto de las víctimas como de la estructuras sociales y económicas que intenta instalar la dictadura. El llamado es claro: no callar, no abandonar las calles. Se niegan rotundamente a aceptar la pseudonormalidad que establece el régimen militar. Rancière dirá:

(...) se supone que el arte es político porque muestra los estigmas de la dominación, o bien porque pone en ridículo los iconos reinantes, o incluso porque sale de los lugares que le son propios para transformarse en práctica social, etc. (2010 54).

Mujeres por la vida estableció una relación horizontal con sus espectadores. En sus acciones no existe una intensión de educarlos, no los subestiman. Todo lo contrario, los dejan libres para que sean ellos mismos quienes construyan su propia mirada, su propia lectura del trabajo que ellas realizan. Este ejercicio permitió ver que sus acciones puedan ser descritas e inscritas como arte crítico. Rancière explica que, cuando hablamos de arte crítico, no existe diferencia entre el artista y su espectador, pues entre ambos se construye la obra; es un igual quien interpela a otro igual, es decir, un a espectador emancipado. Respecto del concepto de "emancipación" Rancière dirá: "Eso es lo que significa la palabra "emancipación": el borramiento de la frontera entre aquellos que actúan y aquellos que miran, entre individuos y miembros de un cuerpo colectivo" (2010 25). Por consiguiente, el espectador al que apela Mujeres por la vida es un espectador emancipado. 
Llevar las discusiones al espacio público es visibilizar las posiciones de todas las personas que caminan por la calle. Proponen ellas un nuevo reparto. En palabras de Rancière, un reparto de lo sensible. Por reparto de lo sensible entendemos "aquello que hace ver quién puede tener parte en lo común en función de lo que hace, del tiempo y el espacio en los cuales esta actividad se ejerce. Tener tal o cual 'ocupación' define competencias e incompetencias respecto de lo común" (Rancière 2000 10). Ellas, justamente, quieren salir de este reparto en el que solo algunos tienen parte. Rancière expone, a propósito de Platón, que los artesanos no pueden ocuparse del común de las cosas porque no tienen tiempo para dedicarse a algo más que no sea su trabajo. Cuando se lleva una problemática al espacio público se pretende que todos nos hagamos parte de las discusiones, plantear nuestras posiciones, opinar, discutir sobre aquello que acontece. No dejamos este "trabajo" en manos de otros, sino que nos asumimos como sujetos políticos activos. Por tanto, estamos hablando de un reparto democrático de lo sensible.

El reparto democrático de lo sensible hace del trabajador un ser doble. Éste saca al artesano de "su" lugar, el espacio doméstico del trabajo, y le da el "tiempo" de estar en el espacio de las discusiones públicas y en la identidad del ciudadano deliberante (Rancière $200054)$.

Si el artesano no trabaja no puede cubrir sus necesidades, por lo tanto, no puede dejar de trabajar, la vida no espera. Su trabajo lo deja fuera, al margen de la participación en lo común y lo confina a un espacio-tiempo privado.

Cuando Rancière invita a pensar en el rol político del arte, invita a pensar precisamente en la forma en que el hacer artístico, la experiencia estética y la obra de arte, intervienen en esas condiciones primeras de la sensibilidad. Condiciones que se encuentran en un plano social, determinadas por las formas sociales mediante un reparto del cual no todos participan e incluso algunos apenas tienen parte. Esta serie de relaciones constituye un partage du sensible. La estética primera, aquellas condiciones primeras de lo sensible en las que nos ubicamos históricamente, operan ya previamente una división, distribución o reparto que fija el lugar de cada cual. En efecto, el trabajo que realiza Mujeres por la vida apuesta por agitar, justamente, esos espacios silenciados por ese reparto. Por eso la necesidad también de ocupar la 
calle como espacio democrático. Se trata de reorganizar este reparto y hacer que todos puedan participar de lo común. Según Rancière, el accionar de esta agrupación se puede concebir como un "hacer artístico", pues interviene la calle y las condiciones primeras de la sensibilidad, $\mathrm{e}$ integra este espacio público a las discusiones borrando las divisiones existentes. Existe aquí un reparto democrático de lo sensible que viene a explicitar de manera aún más clara la mirada que estamos proponiendo sobre el trabajo de Mujeres por la vida. Entonces, un reparto democrático de lo sensible requiere esta permanente verificación del principio de la igualdad, mediante el cual quienes no tenían parte ni voz hacen ver que son parte, se hacen de una voz y muestran que son iguales. De este modo redistribuyen lo sensible. Tal distribución, tal reparto democrático en el ámbito del arte implica la redistribución entre autor y espectador, mediante la cual el espectador se hace de una voz: es parte de la "obra". Por el contrario, la diferenciación entre autor y espectador reproduce la distancia entre goce y trabajo y mantiene la distribución de los que no tienen voz. Por esta razón, la imagen de un nuevo arte crítico se construye a partir de un espectador emancipado, sin elite que verifique el principio de igualdad. Entonces, siguiendo esta ruta, consideramos que el hacer de Mujeres por la vida cuenta con todos los elementos necesarios para constituirse como arte crítico.

Por otro lado, la emancipación se logra por cierta supresión del arte como actividad separada y por la consideración estética de toda actividad, pues toda actividad forma parte del reparto de lo sensible. Es decir, cierta fusión, cierta indistinción fundamental entre la condición artística de cualquier actividad, y de cualquier actividad artística con cualquier otra forma de vida.

Ahora bien, el espectador emancipado apuntará a un reparto emancipado de lo sensible. No es solo un asunto artístico, sino estético. En el régimen estético ${ }^{10}$ el arte puede modificar las formas de sensibilidad,

10 Rancière entiende "régimen estético de las artes" como aquel régimen que identifica propiamente el arte con lo singular y desliga a este arte de toda regla específica, de toda jerarquía de los temas, de los géneros y de las artes. Pero lo realiza haciendo estallar la barrera mimética que distinguía las maneras de hacer del arte de otras maneras de hacer, y separaba sus reglas del orden de ocupaciones sociales. Afirma la absoluta singularidad del arte y destruye al mismo tiempo todo criterio pragmático de esta singularidad. Funda a su vez la autonomía del arte y la identidad de sus formas con aquellas por las cuales la vida se forma ella misma. 
presentes y posibles. Por tal razón, se juega aquí la verdadera posibilidad de la emancipación a través del arte, como proceso de evidenciar la igualdad, lo que Rancière llama también la política. El régimen estético, al intervenir sobre la estética primera y generar un reparto de lo sensible, modifica las relaciones entre policía y política. Es decir, la problemática política se sitúa en un plano muy diferente al del régimen ético. No se trata solo del asunto del contenido de las imágenes que son realizadas como actividad independiente, sino de la manera en que el arte modifica una estética primera que está determinada por las maneras en que se reparte o se distribuye lo sensible, las actividades, las ocupaciones. El arte no aparece entonces como actividad independiente, o como ocupación social específica, sino como el dispositivo que hace visibles tanto los repartos que existen como los posibles. La política sería desde siempre estética. Aquí el nexo entre arte y política queda a la vista y al mismo tiempo evidenciamos que este nexo es central en el trabajo que desarrolla Mujeres por la vida, por lo tanto, su trabajo es un trabajo estético, entendiendo la estética al modo de Rancière. A partir de este concepto proponemos que el trabajo de Mujeres por la vida se puede definir como "insubordinación estética", idea que se desarrollará más adelante.

\section{Jauss y las formas de experiencia artística}

A partir de Jauss intentaremos responder la segunda interrogante que planteamos al comienzo: ¿cómo y desde dónde se genera, en Mujeres por la vida, el deseo de construir esta forma de lenguaje? En primer lugar, el contexto dictatorial en que vivía esta agrupación es central en su trabajo. Eso es lo que las moviliza. Pero ¿por qué crear este tipo de trabajo, por qué crear este material en el que se genera un intenso y fecundo diálogo entre esta agrupación y aquellos que son interpelados? Utilizando los términos que en este trabajo se proponen, nos referiremos a la relación entre artista y espectador.

Como ya mencionamos, la relación que Mujeres por la vida establece con sus interlocutores/espectadores es una relación de iguales, no hay intención de educarlos. Eso hace que exista un trabajo activo y permanente a desarrollar, tanto de ellas como de quienes son interpelados. La permanencia de este trabajo se enmarca en la idea de no olvidar, de negarse a la supuesta "normalidad" que viviera el país, 
salir a tomarse las calles es, justamente, el gesto de no aceptar la normalidad. A partir de Jauss iniciaremos una lectura para reflexionar sobre el trabajo estético que realiza esta "agrupación política ${ }^{11 "}$ y, a partir de ello, preguntaremos qué las lleva a construir estas formas de lenguaje, qué es lo que en ellas acontece. Me parece que esto se explica mejor a partir de la propuesta de Jauss, quien remonta los términos poiesis, aisthesis y catharsis hasta los textos de Aristóteles. Es un gesto al que hay que prestarle mucha atención, aunque sea un recurso extendido y esperable, en la medida en que busca oponerse a la perspectiva platónica que, según Jauss, hay que situar en el origen del ascetismo estético.

Una historia de la experiencia estética, que aún no se ha escrito, debería descubrir la praxis productiva, receptiva y comunicativa del comportamiento estético en una tradición que, en buena medida, ha sido encubierta o ignorada. La tradición de la reflexión teórica del arte, que acompaña al arte occidental por el camino de su autonomía, está totalmente en el bando del platonismo. El platonismo es la herencia dominante en la cual y contra la cual se ha desarrollado la experiencia estética en la historia de la cultura europea (Jauss 1972)

Mediante el análisis de estos tres términos se muestra el carácter del tipo de conocimiento o el resultado que se busca con la reflexión estética propuesta por Jauss. Se trata de un tipo de conocimiento liberador. Aunque aquí la idea de "liberación" es bastante particular. En palabras de Jauss, se libera al sujeto de la extrañeza del mundo mediante la poiesis o actividad productiva. Vivimos en un mundo que no hemos elegido y que tampoco podemos transformar, que es extraño y en el que nos reconocemos como extraños. La poiesis, entendida por Jauss como actividad creadora o productiva genera algo nuevo, en cuanto actividad artística libera de tal extrañeza. Por fin existe algo en el mundo que me pertenece y que puedo experimentar como propio; si tu-

11 Esto es justamente uno de los puntos que nos interesa "desmontar". Mujeres por la vida es una agrupación que se da a conocer en un contexto político muy extremo, una sangrienta dictadura, por lo tanto, la urgencia es política, sin duda. Lo que aquí nos interesa destacar es su quehacer, su trabajo como un hacer estético. La herramienta que utilizan para dar a conocer su postura política es una fórmula estética. El concepto de "estética" lo entenderemos desde la lectura que hace Rancière. 
viera que crear el mundo de nuevo, ese algo seguiría allí. Por lo tanto, el sujeto se libera de aquello predeterminado desde fuera al momento de crear. La experiencia del crear, la poiesis como experiencia artística, conecta desde ya el placer y la liberación.

Nos parece interesante y pertinente pensar el trabajo creativo de Mujeres por la vida a través de estos conceptos propuestos por Jauss. Claro está que la poiesis, en el caso de esta agrupación, no surge de una situación existencial, como es el caso de lo que plantea el autor, sino que de una circunstancia concreta como es la dictadura militar que, de igual modo, produce una situación existencial de indefensión ante la violencia. Vemos en la realización de su trabajo una necesidad de crear algo nuevo, que se traduce en una resistencia a vivir en este régimen de violencia, una resistencia a asumir la "normalidad" que pretende establecer la dictadura. Su trabajo es, justamente, una vía de transformación, hacerse cargo de ese proceso de cambio; no existe el mundo ni el contexto en el cual quisiera vivir, por eso lo transformo. Existe una liberación mediante el trabajo de resistencia, de insubordinación; no puedo cambiar el mundo, pero a través de la actividad productiva, creadora, puedo generar algo propio; por fin existe algo en el mundo que puedo experimentar como propio. El sujeto se libera a través del acto de crear, pero ellas logran cambiar "el mundo", al menos el que las rodea, $\mathrm{o}$ al menos contribuir notablemente a ese cambio.

A partir de esa necesidad de estar fuera, de liberarse de los acontecimientos que se sucedían en el Chile de los 80, Mujeres por la vida logra imaginar un país sin dictadura, sin violencia, sin muerte. No hay imposibles. Situadas en ese margen, trabajan por una democracia basada en la "insubordinación", concepto que proponemos para pensar el accionar de Mujeres por la vida. Muchas veces se puede pensar el trabajo de ésta y diversas agrupaciones políticas como un trabajo de resistencia. Específicamente creemos que esta agrupación va más allá de generar resistencia, pues su trabajo se enmarca como un proceso activo de creación. Además, existe el compromiso de ellas de sumar a los diversos actores sociales a que se hagan parte de esta liberación. No existe una voluntad por liberar a los otros, sino una invitación a hacerse parte de este proceso junto con ellas, una invitación a crear, a producir (se), si se quiere, ese algo nuevo. Este ejercicio de liberación es importante para nosotros, en los diversos conceptos que nos inte- 
resa trabajar a partir de Jauss, y se repetirá de manera significativa al relacionarlo con el trabajo de Mujeres por la vida.

Otro de los conceptos presentados por Jauss, que también nos parece oportuno traer a colación para leer el trabajo de Mujeres por la vida, es el concepto de "aisthesis". Jauss lo entiende como la liberación de la mediocridad o atrofia de lo cotidiano, que en este caso es el mundo del consumo y la extensión de su vulgaridad: la percepción de la obra de arte, su experiencia sensible, rompe con la mediocridad sensible de los objetos de consumo. Nuevamente, es el placer estético, en este caso, el que surge al contacto con la obra y se presenta como una liberación. Es también un remedio por el cual la percepción sensorial es rescatada de la mediocridad sensorial del objeto de consumo. Si nos situamos en el Chile de 1983, entenderemos objeto de consumo como aquello que está allí, como lo inmediato; en este caso, como la supuesta normalidad que nos vendían los medios de comunicación, su negación y silencio sobre los brutales acontecimientos que se producían día a día. Los diarios de la época no mencionaban los crímenes perpetrados por el "gobierno", e incluso se creaban historias ficticias acerca de cómo habían sucedido los crímenes, llenando sus páginas policiales con silenciados asesinatos políticos. Las acciones, intervenciones, documentos, manifestaciones que produce Mujeres por la vida generan las condiciones para que sus interlocutores/espectadores adviertan esa mediocridad sensorial y, a través de ello, realicen el ejercicio de liberación. La intención de esta agrupación es que el interlocutor/ espectador, al encontrarse con una acción, salga de su cotidiano y adopte una posición activa y no la de mirón, que rompa con la mediocridad impuesta. Eso ya es un paso para generar resistencia y no es fácil, el miedo está presente en la mayor parte de la población. En el documental Hoy y no mañana ${ }^{12}$, Kena Lorenzini, fotógrafa perteneciente a esta agrupación, relata que cuando salían a manifestarse se preguntaban entre ellas cuánto miedo tenían y dependiendo de eso se instalaban al principio o al final de la manifestación, evidencia concreta del terror reinante y de las formas de tratar con ello.

12 El documental "Hoy y no mañana" -Distinción Especial INDH (Instituto Nacional de Derechos Humanos)- estrenado en abril de 2019, es dirigido por Josefina Morandé quien se adentró en el mundo de esta agrupación a través de Mónica Echeverría. 
Entonces, podremos decir que la aisthesis es la posibilidad que nos da la obra de romper con lo dado, lo inmediato. Es la posibilidad de liberarnos, a través de nosotros mismos, de la atrofia de lo cotidiano. Nuevamente, la liberación es un ejercicio activo por parte del interlocutor/espectador, y de su completa responsabilidad.

Por último, la satisfacción estética que se genera en la catharsis también se presenta como una liberación, pero en este caso a través de la identificación con el contenido de la obra. Mientras la poiesis implicaba crear algo que ahora es propio, la catharsis implica conectarse con algo ajeno contenido en la obra de otro, pero que ahora me pertenece y me es propio; por medio de la catharsis puedo conectarme con eso otro. En el trabajo de Mujeres por la vida podemos reconocer la catharsis, resultando la relación más bella de los tres conceptos presentados por Jauss, porque evidencia lo que ya venimos mencionando: ellas no pretenden educar a sus interlocutores/espectadores, no quieren que ellos olviden lo que estamos viviendo, una dictadura, que ya en 1983 cumplía una década. En la mayor parte de sus trabajos, especialmente en sus "acciones relámpago", son los interlocutores/espectadores quienes cierran la obra, al mismo tiempo que la completan. En la convocatoria de la acción relámpago: "Soy una víctima de la dictadura. Me torturaron, me asesinaron, me desaparecieron ¿me olvidaste? ${ }^{13}$ ", invitan a una caminata de mujeres en silencio, a las 11:45 de la mañana, especificando que el punto de encuentro sería la Catedral de Santiago y, desde allí, se recorrería el centro portando un afiche. Esta acción se llevó a cabo el lunes 19 de julio de 1988, por el centro de la ciudad, y cada mujer llevó una silueta humana de cartón, pintada de negro, en la que aparecía la frase que daba el nombre a la acción. La intención era interpelar a los transeúntes, dejar la pregunta en suspenso, una pregunta abierta. Esta acción se realizó dos veces; en la segunda la pregunta era mucho más directa, pues llevaba escrito el nombre de distintos detenidos-desaparecidos después del golpe militar. Existen imágenes de esta primera acción que muestran el nivel de violencia y represión de los carabineros de Chile. La catharsis es justamente el resultado que se espera de las acciones/intervenciones que se basan en la irrupción del espacio

13 Acción relámpago realizada en el centro de Santiago, en sus arterias principales, llegando incluso hasta la misma Plaza de Armas de la ciudad. 
público y de lo cotidiano. La catarsis, además de ser una liberación, al igual que las otras dos formas de la experiencia artística, releva a los interlocutores/espectadores a un papel protagónico, y hace que esta lucha de Mujeres por la vida sea la de todos aquellos que vivimos en este país, con un especial énfasis en las mujeres. Un trabajo realizado por mujeres que pretenden visibilizar el papel silenciado de nosotras mismas. Respecto al ejercicio de liberación, Jauss dirá:

La liberación por medio de la experiencia estética puede efectuarse en tres planos: para la conciencia productiva, al engendrar el mundo como su propia obra; para la conciencia receptiva, al aprovechar la posibilidad de percibir el mundo de otra manera, y finalmente -y de este modo la subjetividad se abre a la experiencia intersubjetiva-, al aprobar un juicio exigido por la obra o en la identificación con las normas de acción trazadas y que ulteriormente habrá que determinar (2002 41).

El lenguaje fenomenológico utilizado por Jauss en la cita anterior - conciencia productiva, conciencia receptiva- no debe desviar la atención de este aspecto fundamental de la experiencia artística en sus tres facetas en relación con Mujeres por la vida:

1. Experienciar el acto de crear; experiencia y necesidad que suscita el trabajo de esta agrupación.

2. Percibir una obra como quiebre de la percepción; generar una ruptura con la normalización de una siniestra y silenciada realidad chilena.

3. Permitir un encuentro intersubjetivo, es decir, un encuentro con lo que otro sujeto dice en y por medio de la obra; el sujeto se puede ver reflejado en esa obra, en ese accionar en este caso, y, a partir de ese ejercicio, revisarse.

Quisiera insistir en estas tres dimensiones de la experiencia estética y su proceso liberador que Jauss advierte, y cómo la relacionamos con el trabajo de Mujeres por la vida. En primer lugar, la relación del sujeto con el mundo se ha vuelto extraña, la experiencia que el sujeto tiene en el mundo es inauténtica; el mundo se ha vuelto ajeno. Es decir, esta extrañeza es un quiebre, una ruptura fundamental de la realidad. Por lo tanto, la liberación de esta extrañeza es, en cierto sentido, una reconciliación, una reparación de esa ruptura inicial. El sujeto vive en 
el mundo como un extraño, no está a gusto en él; la poiesis le da la posibilidad de crear, y aquello creado se volverá propio, así el sujeto podrá experimentarse en el objeto y se sentirá en el mundo como si estuviera en casa.

Poiesis, entendida como "capacidad poiética", designa la experiencia estética fundamental de que el hombre, mediante la producción de arte, puede satisfacer su necesidad universal de encontrarse en el mundo como en casa, privando al mundo exterior de su esquiva extrañeza, haciéndola obra propia, y obteniendo en esta actividad un saber que se distingue tanto del conocimiento conceptual de la ciencia como de la praxis instrumental del oficio mecánico (Id. 42).

Proponemos la relación entre poiesis y aquel elemento generador, $\mathrm{y}$ es esta relación la que vemos ubicada en el centro del trabajo de Mujeres por la vida, especialmente es sus documentos escritos, tales como: manifiestos, declaraciones, libretos de consignas, instructivos, convocatorias, panfletos. En estos documentos expresan qué es lo que las mueve a salir de sus espacios privados para generar un espacio político de resistencia e insubordinación de mujeres y para mujeres. Tienen la necesidad imperiosa de salir a la calle, de luchar contra la violencia ejercida por el Estado. Existe la necesidad de trabajar por conseguir un país libre y democrático ${ }^{14}$. En segundo lugar, la relación inauténtica del sujeto con el mundo es la rutina, la vulgaridad de la vida. Se podría establecer una coincidencia con Heidegger, que piensa la cotidianeidad como caída, o con el mismo Adorno, que ve la vulgaridad de lo cotidiano como resultado de la masificación. La aisthesis renueva la percepción que el sujeto tiene del mundo, pues, a través de la obra de arte, se producen nuevas formas de experimentar lo sensible. Y a partir de estas nuevas formas sensibles, el sujeto puede alcanzar una forma de conocimiento distinta a la del saber conceptual.

Aisthesis designa la experiencia estética fundamental de que una obra de arte puede renovar la percepción de las cosas, embotada

14 Creemos interesante destacar la posición de la agrupación frente a la idea de "democracia", y es que, más allá de terminar con la dictadura, ellas apelan a imaginar la democracia, a enfrentarse a esa cultura de la muerte. Un claro ejercicio de insubordinación. 
por la costumbre, de donde se sigue que el conocimiento intuitivo, en virtud de la aisthesis, se opone de nuevo con pleno derecho a la tradicional primacía del conocimiento conceptual (Ibid.).

El trabajo que realiza esta agrupación hace despertar la conciencia de muchas personas, y a otras tantas darse cuenta que no estaban solas en esta necesidad de acabar con la violencia, las torturas, la desapariciones forzadas y la muerte. La aisthesis posee una condición colectiva.

Instalar estos temas en la palestra hace que no podamos rehuir de esta realidad silenciada. A través de las diversas acciones que realiza Mujeres por la vida podemos experimentar un Chile diferente y, de esa manera, comenzar a derribar ciertas narraciones sobre la realidad chilena generadas por la mayoría de los medios de comunicación existentes en esa época.

En tercer lugar, la catharsis permite romper el sometimiento de lo utópico a lo real, del privilegio de una realidad vulgar por sobre una relación heroica, noble. A través de la catharsis el espectador se pone en contacto con las vivencias, los valores, las emociones, las luchas y los fracasos de otros, y los experimenta como propios.

Finalmente, catharsis designa la experiencia estética fundamental de que el contemplador, en la recepción del arte, puede ser liberado de la parcialidad de los intereses vitales prácticos mediante la satisfacción estética y ser conducido asimismo hacia una identificación comunicativa u orientadora de la acción (Id. 43).

Para Mujeres por la vida la recepción de su trabajo es muy importante, la intención es llegar a la mayor cantidad de personas posible, el lugar de la multitud es mucho más atractivo para desarrollar el tipo de acciones propias de la agrupación. Ver qué le sucede al otro a veces resulta más significativo que la obra misma, el deseo de satisfacción que ve en otro lo mueve a involucrarse en la acción. Es interesante leer los instructivos que la agrupación realizaba para invitar a mujeres a, por ejemplo, su día internacional. Específicamente, Instructivo a las Mujeres de Santiago. Día internacional de la mujer 1987 informaba acerca de lo que ocurriría durante las manifestaciones de los días 8, 9 y 10 de marzo. En él, además de detallar hora y actividad, también aparecen los gritos con que se acompañaría la manifestación. Es una guía de qué debíamos hacer aquellas que concurriéramos, dónde 
debíamos instalarnos, qué debíamos gritar. El documento termina diciendo: "No olvidamos en ningún momento que nuestro principal aporte a la lucha contra la dictadura y por nuestros derechos es que en la calle damos un ejemplo vivo de convivencia democrática, todas juntas, respetando el consenso. En nuestra presencia unitaria radica nuestra fuerza. ¡No nos dejemos provocar! ¡Por la democracia y la vida, luchamos unidas!".

Sus interlocutoras son de dos tipos. En un primer caso, las mujeres que participan activamente de sus intervenciones, mujeres que forman parte de organizaciones, a quienes se le hace un llamado directo, y luego está la interlocutora que camina por la calle sin saber lo que pasará. Ambas son receptoras de su trabajo, pero desde lugares diferentes. Sin embargo, la catharsis entrega a ambas la posibilidad de relacionar su praxis vital con el trabajo de la agrupación.

A ambas receptoras se les hace un llamado directo, se les invita a tener una participación activa. Un ejemplo de ello es la acción de: Asamblea del 11 de noviembre de 1985, que realizan: "Por el desistimiento de las querellas contra dirigentes detenidos". Para el desarrollo de esta acción confeccionan un documento-guion dividido en seis puntos: en el primero se habla directamente de "pedir adhesión al público para pedir formalmente al gobierno el desistimiento". Diremos entonces que lo primero que se realiza es la interpelación a todas las personas que pasan por la calle. Mientras tanto, ellas "mostrarán las manos limpias y escribirán en la calle SOMOS MÁS”. El punto 6 se refiere a lo "importante": "a) lograr objetivos; conseguir adhesión: firmas, como concientización y b) hacer el acto pacífico (el subrayado es de ellas)".

Volviendo al concepto mismo de "catarsis", entenderemos que no se trata solo de una liberación de los sentidos y de la percepción, como en el caso de la aisthesis, sino de una liberación de los contenidos que se expresan en los intereses prácticos cotidianos regidos por la necesidad. Es decir, la acción del sujeto, sus decisiones y sus actos, son modelados por estos intereses diarios, prácticos o de la necesidad. La catharsis permite, mediante la identificación con otro sujeto, que puedan ser trastocadas las orientaciones cotidianas de la vida. Los actos del sujeto pueden ser inspirados ahora no solo desde la necesidad de lo cotidiano, sino también por aquellos que descubre en la obra otra 
subjetividad. Y eso es justamente lo que intenta hacer Mujeres por la vida con la irrupción en el espacio público, con la irrupción en la rutina, en lo cotidiano.

Es interesante que la experiencia sensible descrita en estas tres fases sea también un elemento que permite una nueva forma de conocimiento. Jauss utiliza estos tres conceptos de diferente manera a como han sido utilizados tradicionalmente. En este caso se entenderán como conceptos activos, como experiencias. Consecuentemente, la experiencia tiene tres componentes. En primer lugar, una nueva mirada del mundo, o el mundo mirado desde la propia obra, desde la propia creación, es decir el mundo redescubierto en términos artísticos. En segundo lugar, la percepción de lo sensible es un nuevo conocimiento de los objetos del mundo, posibilitado porque la obra rompe la insensibilidad, la atrofia de la percepción sensible. Finalmente, es un nuevo conocimiento en cuanto a los propios actos, deseos y decisiones, que ya no solo son observados a través del prisma de las necesidades diarias, sino del espejo de otra subjetividad sometida a sus propias necesidades e inquietudes.

Vale la pena mantener a la vista los dos polos de extrañeza: el polo existencial, es decir, que la extrañeza existe porque el mundo es distinto al sujeto y hay una distancia existencial insalvable entre ambos; pero también hay que tener a la vista el componente político-cultural, es decir, que esta extrañeza existe porque el mundo se vuelve extraño en la cultura masificada de los objetos de consumo, que atrofian la experiencia de lo sensible y someten al sujeto a la pura necesidad de lo cotidiano. Es, justamente, este segundo componente el que más se ajusta al análisis que hemos intentado desarrollar en este texto.

\section{Conclusiones}

El presente trabajo propone instalar una nueva mirada sobre el trabajo que realizó Mujeres por la vida, valorarlo y, a partir de ello, hacer ingresar a esta agrupación al registro del arte contemporáneo chileno; repensarlo concibiéndolo como un trabajo estético. Entendemos que para ellas el proyecto político es central, no lo desconocemos, la primera convocatoria es política, es allí donde está la urgencia. Es justamente esa urgencia política lo que las hace buscar algún soporte artístico-visual para transmitir un mensaje político. 
Al abordar el trabajo de Mujeres por la vida creemos que lo trascendental para ellas, como agrupación, es la lucha constante y sistemática por la obtención de la democracia. Por esta razón, el uso de la calle, del espacio público, es el elemento central para la visibilización de la protesta en contra de la dictadura. En otras palabras, su propuesta se juega en la calle como espacio de visibilización de la oposición al régimen de muerte. A partir de ello construyen un lenguaje que pone en evidencia los acontecimientos de violencia que se viven diariamente en todo Chile. Además de los acontecimientos, creemos que la intención es mostrar las posiciones políticas que tenían las diversas personas frente a estos actos, tomando en cuenta que la prensa de la época estaba capturada por el mismo régimen, que insistía en mostrar que vivíamos una "normalidad" y que todos estábamos conformes con la supuesta activación económica que vivía Chile. Lo que nos interesa destacar es la manera en que resuelven que su salida a la calle es para buscar adeptos que se sumen a esta lucha junto a ellas. No es una tarea que ellas pretender asumir solas, sino que quieren que seamos muchas quienes salgamos a ocupar el espacio público y mostremos nuestro descontento. Este ejercicio va más allá que generar una resistencia, es una invitación a la insubordinación colectiva. Ejemplo de ello son sus manifestaciones que siempre son una invitación abierta a todas las mujeres, específicamente, a salir a la calle. Este ejercicio de intervenir la ciudad de manera efímera es un ejercicio que pretende interrumpir el paso de las personas que caminan por la calle, interrumpir su flujo cotidiano. Dicho esto, entendemos que su propuesta se podrá dividir entre fondo y forma. El fondo como aquello que se han propuesto conseguir - la democracia- y la forma el modo de trabajo. En este caso la forma la entenderemos como insubordinación, una insubordinación estética.

\section{Bibliografía}

Arrieta, D. y, Alejandra Matus, A. Un padre desesperado. Las historias reales que inspiran la serie Los archivos del Cardenal: Los casos de la vicaría. Disponible en http://www.casosvicaria. cl/temporada-uno/un-padre-desesperado/

Jauss, Hans Robert. Experiencia estética y hermenéutica literaria. Madrid, España: Taurus, 1986. 
Jauss, Hans Robert. Pequeña apología de la experiencia estética. Barcelona, España: Paidós, 2002.

Movimiento Contra la Tortura Sebastián Acevedo. "Informativo $\mathrm{N}^{\circ} 1$ ". Concepción, Chile. Biblioteca digital Museo de la Memoria y los Derechos Humanos. Textos y manuscritos, diciembre de 1983.

Mujeres por la vida. "A la opinión pública". Santiago, Chile. Biblioteca digital Museo de la Memoria y los Derechos Humanos. Textos y manuscritos, 2 de octubre de 1987.

Mujeres por la vida. “Apuntes para la reflexión". Santiago, Chile. Biblioteca digital Museo de la Memoria y los Derechos Humanos. Textos y manuscritos, 4 de marzo de 1987.

Mujeres por la vida. "Hoy y no mañana". Santiago, Chile. Biblioteca digital Museo de la Memoria y los Derechos Humanos. Textos y manuscritos, 16 de noviembre de 1983.

Mujeres por la vida. "Instructivo a las Mujeres de Santiago, Día Internacional de la Mujer". Santiago, Chile. Biblioteca digital Museo de la Memoria y los Derechos Humanos. Textos y manuscritos, 30 de octubre de 1986.

Mujeres por la vida. "Instructivo Acto 11 de septiembre". Santiago, Chile. Biblioteca digital Museo de la Memoria y los Derechos Humanos. Textos y manuscritos, 11 de septiembre.

Mujeres por la vida. "Sugerencias para los manifestantes". Santiago, Chile. Biblioteca digital Museo de la Memoria y los Derechos Humanos. Textos y manuscritos.

Museo de la Memoria y los Derechos Humanos. "Comisión Antirrepresiva CODEPU". "Informativo Regional". Concepción, Chile: Biblioteca digital. Textos y manuscritos Museo de la Memoria y los Derechos Humanos, Textos y manuscritos.

Museo de la Memoria y los Derechos Humanos. $2^{\circ}$ Juzgado del crimen de Concepción. "Expediente Judicial muerte de Sebastián Acevedo". Concepción, Chile: Biblioteca digital. Textos y manuscritos, Biblioteca digital Museo de la Memoria y los Derechos Humanos. Textos y manuscritos, 23 de diciembre de 1983.

Platón. La República. Madrid, España: Gredos, 1988.

Rancière, Jacques. El espectador emancipado. Buenos Aires, Argentina: Manantial, 2010. 
Rancière, Jacques. El malestar en la estética. Madrid, España: Clave Intelectual, 2012.

Rancière, Jacques. El reparto de lo sensible. Santiago, Chile: LOM, 2000. Red de conceptualismo Conceptualismo del surSur. Perder la forma humana. Una imagen sísmica de los años ochenta en América Latina. Madrid, España: Museo Reina Sofía, 2012 